\title{
Metabolism and Disposition of a Novel Selective $\alpha 7$ Neuronal Acetylcholine Receptor Agonist ABT-126 in Humans: Characterization of the Major Roles for Flavin-Containing Monooxygenases and UDP-Glucuronosyl Transferase 1A4 and 2B10 in Catalysis $^{\mathbb{S}}$
}

\author{
Hong Liu, ${ }^{1}$ David M. Stresser, Melissa J. Michmerhuizen, Xiaofeng Li, Ahmed A. Othman, \\ Aimee D. Reed, Michael R. Schrimpf, Jens Sydor, and Anthony J. Lee ${ }^{2}$ \\ Bioanalysis and Biotransformation (H.L., M.J.M., J.S., A.J.L.), DMPK and Translational Modeling (D.M.S., X.L.), Process Chemistry \\ (A.D.R.), Discovery Chemistry and Technology (M.R.S.), and Clinical Pharmacology and Pharmacometrics (A.A.O.), Research and \\ Development, AbbVie, North Chicago, Illinois
}

Received July 12, 2017; accepted January 11, 2018

\begin{abstract}
Mass balance, metabolism, and excretion of ABT-126, an $\alpha 7$ neuronal acetylcholine receptor agonist, were characterized in healthy male subjects $(n=4)$ after a single $100-\mathrm{mg}(100 \mu \mathrm{Ci})$ oral dose. The total recovery of the administered radioactivity was $94.0 \%$ $( \pm 2.09 \%)$, with $81.5 \%( \pm 10.2 \%)$ in urine and $12.4 \%( \pm 9.3 \%)$ in feces. Metabolite profiling indicated that ABT-126 had been extensively metabolized, with $6.6 \%$ of the dose remaining as unchanged parent drug in urine. Parent drug accounted for $12.2 \%$ of the administered radioactivity in feces. The primary metabolic transformations of ABT-126 involved aza-adamantane $\mathrm{N}$-oxidation (M1, 50.3\% in urine) and aza-adamantane $\mathrm{N}$-glucuronidation (M11, 19.9\% in urine). M1 and M11 were also major circulating metabolites, accounting for $32.6 \%$ and $36.6 \%$ of the drug-related material in plasma, respectively. These results demonstrated that ABT-126 is eliminated primarily by
\end{abstract}

hepatic metabolism, followed by urinary excretion. Enzymatic studies suggested that M1 formation is mediated primarily by human liver flavin-containing monooxygenase (FMO) 3 and, to a lesser extent, by human kidney FMO1; M11 is generated mainly by human uridine 5' -diphospho-glucuronosyltransferase (UGT) 1A4, whereas UGT 2B10 also contributes to ABT-126 glucuronidation. Species-dependent formation of M11 was observed in hepatocytes; M11 was formed in human and monkey hepatocytes, but not in rat and dog hepatocytes, suggesting that monkeys constitute an appropriate model for predicting the fate of compounds undergoing significant $\mathrm{N}$-glucuronidation. M1 and M11 are not expected to have clinically relevant on- or off-target pharmacologic activities. In summary, this study characterized ABT-126 metabolites in the circulation and excreta and the primary elimination pathways of ABT-126 in humans.
Introduction

Alzheimer disease (AD) is a chronic neurodegenerative disease and the most common cause of dementia. As of 2016, an estimated 5.4 million Americans have AD (Alzheimer's Association, 2016). The few available treatments for $\mathrm{AD}$ [acetylcholine esterase inhibitors and $N$-methyl-Daspartate receptor antagonists] provide temporary improvement in cognition, but none of them slows or stops the damage of neurons that cause symptoms of $\mathrm{AD}$. There is a clear medical need for new therapy to treat this disease.

The $\alpha 7$ neuronal acetylcholine receptors (nAChRs) are acetylcholinegated cation channels that are localized on the brain regions critical to the

${ }^{1}$ Current affiliation: Novartis Institutes for BioMedical Research Pharmacokinetic Sciences, Cambridge, Massachusetts; ${ }^{2}$ Seattle Genetics, Bothell, WA https://doi.org/10.1124/dmd.117.077511.

S This article has supplemental material available at dmd.aspetjournals.org. synaptic plasticity underlying learning and memory. Activation of $\alpha 7$ nAChRs can cause the release of neurotransmitters (GABA, acetylcholine [ACh], and glutamate) important for cognition (Lendvai et al., 2013). Several studies suggest that $\alpha 7 \mathrm{nAChR}$ plays a significant role in the development of AD pathology (Gotti and Clementi, 2004; Roncarati et al., 2009). The $\alpha 7 \mathrm{nAChR}$ agonist under development by EnVivo (EVP-6124) has shown the potential in the treatment of AD (Deardorff et al., 2015).

ABT-126 is a potent and selective $\alpha 7 \mathrm{nAChR}$ agonist with high binding affinity $\left(K_{\mathrm{i}}=12-14 \mathrm{nM}\right)$ to $\alpha 7 \mathrm{nAChRs}$ (human, rat, or mouse cortex) (Gault et al., 2016). ABT-126 shows significantly less affinity ( $>140$-fold) toward other nAChR subtypes and muscarinic receptor and therefore is expected to eliminate the dose-limiting toxicity associated with acetylcholine esterase inhibitors. ABT-126 exhibits a preclinical efficacy profile across multiple cognitive domains of relevance to AD. ABT-126 was evaluated in single-dose and multiple dose phase 1 studies, and doses up to $150 \mathrm{mg}$ once daily or up to $40 \mathrm{mg}$ twice a day were generally well tolerated (AbbVie internal data). The results of a

ABBREVIATIONS: AD, Alzheimer disease; AUC, area under the curve; FMO, flavin-containing monooxygenase; HKM, human kidney microsome; HLM, human liver microsome; HPLC, high-performance liquid chromatography; LC-MS/MS, liquid chromatography-tandem mass spectrometry; LLOQ, lower limit of quantitation; LSC, liquid scintillation counting; nAChRs, neuronal acetylcholine receptors; P450, cytochrome P450; PD, pharmacodynamic; PK, pharmacokinetic; SPE, solid-phase extraction; UGT, uridine 5'-diphospho-glucuronosyltransferase. 
phase $2 \mathrm{a}$ trial indicated that treatment with ABT-126 was associated with a trend for improvement in cognition in subjects with mild to moderated AD (Gault et al., 2015); however, the subsequent phase $2 b$ trial encompassing a broader dose range did not demonstrate statistically significant improvement versus a placebo control (Florian et al., 2016; Gault et al., 2016). In another phase 2 a trial in subjects with schizophrenia, ABT-126 demonstrated a precognitive effect in nonsmoking subjects, particularly in verbal learning, working memory, and attention (Haig et al., 2016b). A follow-up dose-ranging study showed that ABT-126 did not demonstrate a consistent effect on cognition in nonsmoking subjects with schizophrenia; however, a trend toward a therapeutic effect was observed on negative symptoms (Haig et al., 2016a).

The objectives of the current study were to determine the mass balance and routes of excretion, characterize the major metabolites of ABT-126 in healthy human volunteers, and identify the major enzymes catalyzing the biotransformation of ABT-126.

\section{Materials and Methods}

Drugs and Reagents. The chemical names for ABT-126, M1, M11, and M12 are 2-((1r,3R,4s,5S,7s)-1-azaadamantan-4-yloxy)-5-phenyl-1,3,4-thiadiazole, ((1s,3R,4s, 5S, 7s)-4-((5-phenyl-[1,3,4]thiadiazol-2-yl)oxy)-1-azaadamantane-1oxide), (2S,3S,4S,5R,6S)-3,4,5-trihydroxy-6-((1s,3R,4R,5S,7R)-4-((5-phenyl-1,3,4thiadiazol-2-yl)oxy)-1-azaadamantan-1-ium-1-yl)tetrahydro-2H-pyran-2-carboxylate, (1s,3R,4S,5S,7S)-4-((5-phenyl-1,3,4-thiadiazol-2-yl)oxy)-1-((2R,3R,4S,5S,6R)3,4,5-trihydroxy-6-(hydroxymethyl)tetrahydro-2H-pyran-2-yl)-1-azaadamantan-1-ium, respectively. ABT-126, M1, M11, and M12 reference standards were supplied by Process Chemistry, AbbVie, Inc. (North Chicago, IL) and were used as highperformance liquid chromatography (HPLC) and mass spectrometric (MS) standards. The synthesis of M1, M11, and M12 are provided in the supplemental data. $\left[{ }^{3} \mathrm{H}\right] \mathrm{ABT}-126$ was synthesized in one step by hydrogenolysis of the corresponding bromo-precursor (2-((1r,3R,4s,5S,7s)-1-azaadamantan-4-yloxy)5-(3-bromophenyl)-1,3,4-thiadiazole). Radiochemical purity after HPLC purification of $\left[{ }^{3} \mathrm{H}\right] \mathrm{ABT}-126$ was $>99 \%$. $\left[{ }^{14} \mathrm{C}\right] \mathrm{ABT}-126$ was synthesized in three steps starting from $\left[{ }^{14} \mathrm{C}\right]$ carbonyl labeled benzoic acid. Purification of the compound by crystallization provided $>98 \%$ radiochemical purity by HPLC. More detailed synthetic procedures were provided in the supplemental data. Chemical structures of $\left[{ }^{3} \mathrm{H}\right] \mathrm{ABT}-126\left(\mathrm{~T}\right.$ denotes $\left.{ }^{3} \mathrm{H}\right)$ and $\left[{ }^{14} \mathrm{C}\right] \mathrm{ABT}-126\left(*\right.$ denotes $\left.{ }^{14} \mathrm{C}\right)$ are shown in Supplemental Fig. S1.

All HPLC-grade solvents used for liquid chromatography-tandem mass spectrometry (LC-MS/MS) analysis were purchased from Sigma-Aldrich (St. Louis, MO). The scintillation fluids used for radioanalysis were purchased from PerkinElmer (Waltham, MA). Cryopreserved hepatocytes from male Sprague-Dawley rats (lot TIJ), male beagle dogs (lot BWX), male cynomolgus monkeys (lot EHH), and humans (lot AOI) were purchased from BioreclamationIVT (Chestertown, MD). Corning Supersomes prepared from control baculovirus-infected insect cells expressing human cytochrome P450 (P450) isoforms 1A2, 2A6, 2B6, 2C8, 2C9, 2C18, 2C19, 2D6, 2E1, 3A4, flavincontaining monooxygenase ((FMO) isoforms FMO1, FMO3, FMO5, and UGT isoforms $1 \mathrm{~A} 1,1 \mathrm{~A} 3,1 \mathrm{~A} 4,1 \mathrm{~A} 6,1 \mathrm{~A} 7,1 \mathrm{~A} 9,1 \mathrm{~A} 10,2 \mathrm{~B} 4,2 \mathrm{~B} 7,2 \mathrm{~B} 10,2 \mathrm{~B} 15$, and 2B17 were obtained from Corning Life Sciences (Woburn, MA). Pooled human liver (HLMs) and kidney microsomes (HKMs) were obtained from Sekisui Xenotech (Kansas City, KS).

Clinical Study. The clinical study was conducted at Covance Laboratories Inc., in conjunction with the Covance Clinical Research Unit (Madison, WI). This was a phase 1 , single radiolabeled dose, open-label, single-center, mass balance study. The study was conducted in accordance with Good Clinical Practice guidelines and ethical principles that have their origin in the Declaration of Helsinki. The study protocol was approved by the institutional review board and all subjects provided written informed consent before any study-related procedures were performed. The radioactive dose of $100 \mu \mathrm{Ci}$ was chosen so that the radiation burden for healthy volunteers remained below the allowable United States Food and Drug Administration whole-body exposure limits of $3000 \mathrm{mRem}$ for a single dose of radioactivity. The single dose of $100 \mathrm{mg}$ ABT-126 for this open-label study was selected based on the available pharmacokinetic $(\mathrm{PK}) /$ pharmacodynamics $(\mathrm{PD})$ and safety information. In a phase 1 study of ABT-126 in healthy adult subjects, doses up to $150 \mathrm{mg}$ daily for up to 10 days had been safe and well tolerated with no clinically significant adverse effects reported (AbbVie internal data).

A total of four male subjects, in general good health, were selected to participate in the study according to predetermined criteria. On the morning of study day 1 , subjects received a single oral dose of $\left[{ }^{14} \mathrm{C}\right] \mathrm{ABT}-126$ with approximately $240 \mathrm{ml}$ of water approximately 30 minutes after completion of a standardized breakfast. Subjects were confined to the study site and supervised beginning on study day 1 and continuing through 192 hours after dosing and completion of study activities. Subjects were released from the study site at any time after 192 hours post dose, once either of the following conditions was met: 1) $>90 \%$ of the total radioactivity was recovered, or 2$)<1 \%$ of the radioactive dose was recovered in two consecutive 24-hour collection periods.

Blood samples were collected by venipuncture into vacutainer collection tubes containing di-potassium ethylenediaminetetraacetate at the following time points: 0 (predose), $0.5,1,2,3,4,6,9,12,16,24,48,72,96,120,144,168,192$, and 216 hours after $\left[{ }^{14} \mathrm{C}\right] \mathrm{ABT}-126$ dosing. Plasma was separated via centrifugation and stored at $-70^{\circ} \mathrm{C}$.

Urine samples were collected predose and over the following intervals: $0-8$, 8-24, 24-48, 48-72, 72-96, 96-120, 120-144, 144-168, 168-192, and 192-216 hours after $\left[{ }^{14} \mathrm{C}\right] \mathrm{ABT}-126$ dosing. Aliquots of the urine were frozen and maintained at $-70^{\circ} \mathrm{C}$ before total radioactivity determination and metabolite profile and identification.

Fecal samples were collected predose (upon check-in before dosing) and over the following intervals after dosing: 0-24, 24-48, 48-72, 72-96, 96-120, $120-144,144-168,168-192$, and 192-216 hours after dosing of $\left[{ }^{14} \mathrm{C}\right] \mathrm{ABT}-126$ on study day 1 . All feces collected during a collection interval were kept frozen at $-70^{\circ} \mathrm{C}$ before total radioactivity analysis and metabolite profile and identification.

Total Radioactivity Measurement by Liquid Scintillation Counting. All sample combustions were conducted in a model 307 Sample Oxidizer (Packard Instrument Company, Meriden, CT), and the resulting ${ }^{14} \mathrm{CO}_{2}$ was trapped in Carbo-Sorb and mixed with aqueous mounting medium (PermaFluor; PerkinElmer). Oxidation efficiency was evaluated on each day of sample combustion by analyzing a commercial radiolabeled standard both directly in scintillation cocktail and by oxidation. Acceptance criteria were combustion recoveries of 95\%-105\%. EcoLite(+) scintillation cocktail was used for samples analyzed directly. All samples were analyzed for radioactivity in model 2900TR liquid scintillation counters (Packard Instrument Company) for at least 5 minutes or 100,000 counts. Each sample was homogenized or mixed before radioanalysis (unless the entire sample was used for analysis). All samples were analyzed in duplicate if sample size allowed. If results from sample replicates (calculated as ${ }^{14} \mathrm{C} \mathrm{dpm} / \mathrm{g}$ sample) differed by $>10 \%$ from the mean value, and sample aliquots had radioactivity $>200 \mathrm{dpm}$, the sample was rehomogenized or remixed and reanalyzed (if the sample size permitted). Scintillation counting data ( $\mathrm{cpm}$ ) were automatically corrected for counting efficiency using the external standardization technique and an instrument-stored quench curve generated from a series of sealed quenched standards

Blood samples were mixed, and duplicate weighed aliquots (approximately $0.1-0.2 \mathrm{~g}$ ) were combusted and analyzed by liquid scintillation counting (LSC). The representative lower limit of quantitation (LLOQ) for blood was $49.6 \mathrm{ng}$ equivalents/g. Plasma samples were mixed, and duplicate weighed aliquots (approximately $0.2 \mathrm{~g}$ ) were analyzed directly by LSC. The representative LLOQ for plasma was $40.1 \mathrm{ng}$ equivalents/g. The urine samples were mixed, and duplicate weighed aliquots (approximately $0.2 \mathrm{~g}$ ) were analyzed directly by LSC. The representative LLOQ for urine was $35.9 \mathrm{ng}$ equivalents/g. Fecal samples were combined by subject at 24-hour intervals, and the weight of each combined sample was recorded. A weighed amount of water was added, and the sample was mixed. The sample was either immediately homogenized or removed from the freezer and homogenized using a probe-type homogenizer. Duplicate weighed aliquots (approximately $0.2 \mathrm{~g}$ ) were combusted and analyzed by LSC. The representative LLOQ for feces was $253 \mathrm{ng}$ equivalents/g.

Sample Preparation for Metabolite Profiling. Plasma samples were thawed at room temperature and pooled across subjects at selected time points or area under the curve (AUC) pooled per subject using the method of Hamilton et al. (1981). Plasma samples were processed using a solvent extraction method. In brief, the pooled plasma sample $(4 \mathrm{ml})$ was extracted with a 4-fold volume of acetonitrile/methanol (3/1, v/v), followed by sonication and vortex mixing. 
The sample was centrifuged at $1875 \mathrm{~g}$ for 30 minutes at $4^{\circ} \mathrm{C}$. The protein pellets were extracted using $8 \mathrm{ml}$ of acetonitrile/methanol (3/1, v/v), followed by centrifugation at $1875 \mathrm{~g}$. The supernatants were combined and concentrated to about $200 \mu 1$ under a stream of nitrogen; the residue was diluted with $200 \mu 1$ of methanol/ $/ 0.1 \%$ formic acid in water $(1 / 1, \mathrm{v} / \mathrm{v})$ before HPLC-MS-radioflow detection. An aliquot of the reconstituted sample was subjected to LSC counting to determine the total radioactivity recovery. Aliquot of the reconstituted sample was transferred to HPLC autosampler vials for LC-MS analysis. The radioactivity recovery in the processed plasma samples ranged from $80 \%$ to $100 \%$.

An equal volume of fecal homogenate was pooled across subjects at each time point before processing. The pooled fecal samples $(30-40 \mathrm{ml})$ were processed using solvent extraction with $20 \mathrm{ml}$ of acetonitrile/methanol (3/1, v/v), followed by centrifugation at $1875 \mathrm{~g}$ for 30 minutes at $4^{\circ} \mathrm{C}$. The extraction was repeated with $10 \mathrm{ml}$ of acetonitrile/methanol $(3 / 1, \mathrm{v} / \mathrm{v})$, followed by centrifugation at $1875 g$ for 30 minutes at $4^{\circ} \mathrm{C}$. Aliquots of extracted sample were subjected to LSC counting for total radioactivity. All the supernatants were combined and concentrated under nitrogen flow at room temperature. The concentrated samples $(\sim 10 \mathrm{ml})$ were combined with $5 \mathrm{ml}$ of acetonitrile/methanol $(3 / 1, \mathrm{v} / \mathrm{v})$. The resulting solution was vortexed, sonicated, and centrifuged at $1875 \mathrm{~g}$ for 30 minutes at $4{ }^{\circ} \mathrm{C}$. An aliquot was subjected to HPLC-MS radioflow detection analysis for metabolite characterization. An aliquot of solution was subjected to LSC radiocounting for extraction recovery calculation. The overall radioactivity recovery for fecal samples ranged from $61 \%$ to $100 \%$.

An equal volume of urine sample was pooled across subjects at each time point and processed by centrifugation at $1875 \mathrm{~g}$ for 30 minutes at $4^{\circ} \mathrm{C}$. Aliquots of supernatant at $0-8,8-24,24-48,48-72$, and $72-96$ hours were used directly for HPLC-MS radioflow detection. Pooled urine samples at 96-120, 120-144, 144-168, 168-192, and 192-216 hours were concentrated under nitrogen flow at room temperature to $\sim 1.7 \mathrm{ml}$ for analysis. The overall radioactivity recovery for urine samples ranged from $84 \%$ to $100 \%$.

Method for Metabolite Profiling and Identification. HPLC separation of ABT-126 and metabolites in human plasma, urine, and feces was achieved using a Thermo Accela ultra-HPLC system (ThermoFisher Scientific, Waltham, MA), which consisted of an Accela autosampler and 1250 series binary pump. For in vitro samples from hepatocytes and enzyme phenotyping studies, HPLC separation was achieved using an Agilent 1100 Series (Thermo Fisher Scientific), which consisted of an autosampler and quaternary pump. Separation for all samples was achieved at room temperature on a Phenomenex Luna C8 (2), $5 \mu \mathrm{m}$, $4.6 \times 250 \mathrm{~mm}$ HPLC column. The HPLC mobile phases consisted of $25 \mathrm{mM}$ ammonium formate (adjusted to $\mathrm{pH} 3.5$ with formic acid) containing 2.5\% methanol (solvent A) and $100 \%$ acetonitrile (solvent B); the flow rate was maintained at $1.0 \mathrm{ml} / \mathrm{min}$. The gradient for human plasma, urine, and feces was as follows: 0-30 minutes, $10 \%-18 \%$ solvent $\mathrm{B}$; $30-60$ minutes, $18 \%-22 \%$ solvent $\mathrm{B}$; 60 to 61 minutes, $22 \%-90 \%$ solvent B; $61-65$ minutes, $90 \%$ solvent $\mathrm{B}$; 65-66 minutes, $90 \%-10 \%$ solvent B; 66-76 minutes, and $10 \%$ solvent $\mathrm{B}$. The gradient for in vitro samples was as follows: 0-35 minutes, 5\%-30\% solvent B; 35-36 minutes, 30\%-80\% solvent $\mathrm{B}$; 36-40 minutes, $80 \%$ solvent $\mathrm{B}$; 40-41 minutes, $80 \%-5 \%$ solvent B; and $41-51$ minutes, $5 \%$ solvent B. For samples from human plasma, urine, and feces, the HPLC system was interfaced with a Thermo Fisher LTQ Orbitrap mass spectrometer (Thermo Fisher Scientific). The mass spectrometer used for in vitro samples analysis from hepatocytes and enzyme phenotyping studies was a LCQ Deca XP MAX (Thermo Fisher Scientific). The MS analyses were conducted using electrospray ionization operated in positive ionization mode. The MS settings were as follows: electrospray ionization voltage, $4.5 \mathrm{kV}$; capillary temperature, $350^{\circ} \mathrm{C}$; capillary voltage, $14 \mathrm{~V}$; tube lens, $105 \mathrm{~V}$. The sheath gas was set to 45.0 arbitrary units and auxiliary gas to 0 arbitrary unit. The unchanged parent drug and its metabolites were detected using data-dependent, multiple-stage mass analysis, and normalized collision energy of $35 \%$ for both tandem MS $\left(\mathrm{MS}^{2}\right)$ and multiple-stage MS $\left(\mathrm{MS}^{3}\right)$. For sample analysis from human plasma, urine, and feces, the mass resolution was set at 30,000 for full scan and 15,000 for $\mathrm{MS}^{\mathrm{n}}$ scan. The instrument was calibrated daily using external calibration reference compounds. Typical mass errors of analytes relative to theoretical masses were less than $\pm 5 \mathrm{ppm}$ in daily operations. Data acquisition and processing were carried out using Thermo Xcalibur 2.10.

Radiolabeled components in plasma, urine, or fecal samples were detected by Perkin Elmer TopCount 96-well LUMA plates (Perkin Elmer). The HPLC eluent was split in a ratio of $1: 4$; about $200 \mu \mathrm{l} / \mathrm{min}$ of flow was diverted to mass spectrometer, and $\sim 800 \mu \mathrm{l} / \mathrm{min}$ flow was collected using Agilent 1100 fraction collection system set at 0.27 -minute interval per well collection. Radiolabeled components from in vitro samples were detected by a Packard 500 TR flow scintillation detector equipped with a $250 \mu \mathrm{l}$ cell. Data were processed using the Radiomatic Flo-one software v3.65. The scintillant (Perkin Elmer FLO-SINT III) flow was maintained at $3 \mathrm{ml} / \mathrm{min}$.

LC-MS/MS Analysis for In Vitro Samples. Samples from M1 and M11 formation kinetics were analyzed by multiple reaction monitoring on an LC-MS/MS system consisting of Agilent 1290 HPLC pump (Agilent, Santa Clara, CA), CTC PAL autosampler (Leap Technologies, Carrboro, NC), and an API 5500 MS system equipped with an electrospray ion source and operated by the Analyst software package (Applied Biosystems, Foster City, CA). The source temperature was set to $600^{\circ} \mathrm{C}$. Chromatography was conducted on a Fortis Pace $\mathrm{C} 18(30 \times 2.1 \mathrm{~mm})$ analytical column. The HPLC mobile phases consisted of $0.1 \%$ formic acid in water (solvent $\mathrm{A}$ ) and $0.1 \%$ formic acid in acetonitrile (solvent $\mathrm{B}$ ); the flow rate was maintained at $0.8 \mathrm{ml} / \mathrm{min}$ The gradient was as follows: $0-0.05$ minutes, 5\% solvent $\mathrm{B} ; 0.05-0.3$ minutes, $5 \%-98 \%$ solvent $\mathrm{B}$; $0.3-0.7$ minutes, $98 \%$ solvent $\mathrm{B}$; $0.7-0.8$ minutes, $98 \%-5 \%$ solvent $\mathrm{B}$; and $0.8-0.9$ minutes, $5 \%$ solvent B. M1 $(\mathrm{m} / \mathrm{z}, 329.8 \rightarrow 135.9)$, M11 $(\mathrm{m} / \mathrm{z}, 490.2 \rightarrow 314.1)$, and internal standard carbutamide $(\mathrm{m} / 2,272.2 \rightarrow 108.1)$ were detected in positive ion mode.

Pharmacokinetic Calculations. Values for the PK parameters of total radioactivity, ABT-126, M1, and M11 were determined using noncompartmental methods. Parameters that were estimated included the maximum plasma concentration $\left(C_{\max }\right)$, the time to $C_{\max }\left(T_{\max }\right)$, and the area under the concentration-time curve from time 0 to the last measurable time point $\left(\mathrm{AUC}_{\mathrm{t}}\right)$ and to infinite time $\left(\mathrm{AUC}_{\infty}\right)$.

In Vitro Hepatocytes Incubations. Incubations were performed in duplicate at $37^{\circ} \mathrm{C}$ in $5 \% \mathrm{CO}_{2} / 95 \%$ air, with gentle shaking. Each incubation contained $1 \mu \mathrm{M}$ $\left[{ }^{3} \mathrm{H}\right] \mathrm{ABT}-126$ and thawed cryopreserved hepatocytes $(500,000$ viable cells $/ \mathrm{ml}$, $0.5 \mathrm{ml}$ ). The reaction was quenched by the addition of $1 \mathrm{ml}$ of acetonitrile/methanol $(1 / 1, \mathrm{v} / \mathrm{v})$ at $0,0.5,1,2$, and 4 hours after the addition of $\left[{ }^{3} \mathrm{H}\right] \mathrm{ABT}-126$. Samples were centrifuged for 30 minutes at $1279 g$ (Eppendorf $5810 \mathrm{R}$ centrifuge), and resulting supernatants were analyzed by HPLC-MS/MS with radioflow detection. Detailed analytical conditions are described in the Method for Metabolite Profiling and Identification section.

CYP/FMO Phenotyping and Kinetics. The in vitro oxidative metabolism of $\left[{ }^{3} \mathrm{H}\right] \mathrm{ABT}-126$ was investigated using a panel of recombinant human P450 enzymes (CYP1A2, 2A6, 2B6, 2C8, 2C9, 2C18, 2C19, 2D6, 2E1, 3A4) and FMO enzymes (FMO1, FMO3, and FMO5). An incubation mixture (200 $\mu$ l) contained individual P450 isoforms at $100 \mathrm{pmol} / \mathrm{ml}(200 \mathrm{pmol} / \mathrm{ml}$ for CYP2C8) or FMO1, FMO3, FMO5 at $0.5 \mathrm{mg}$ protein $/ \mathrm{ml}$, respectively, and $\left[{ }^{3} \mathrm{H}\right] \mathrm{ABT}-126(1 \mu \mathrm{M})$ in $50 \mathrm{mM}$ potassium phosphate buffer at $\mathrm{pH}$ 7.4. The reaction was initiated by the addition of $1 \mathrm{mM}$ of NADPH and incubated at $37^{\circ} \mathrm{C}$ for 60 minutes. The reaction was terminated by the addition of $200 \mu \mathrm{l}$ of acetonitrile/methanol $(1 / 1, \mathrm{v} / \mathrm{v})$. After vortexing and centrifugation, the supernatants were analyzed by HPLC analysis with radioactivity detection. Detailed analytical conditions are described in the Method for Metabolite Profiling and Identification section.

To determine enzyme kinetic parameters for the formation of M1, incubations containing ABT-126 at varying concentrations $(0.3-150 \mu \mathrm{M})$ were conducted in triplicate with recombinant FMO1 $(0.05 \mathrm{mg} / \mathrm{ml}, 10$ minutes $)$ and FMO3 $\left(0.1 \mathrm{mg} / \mathrm{ml}, 10\right.$ minutes) at $37^{\circ} \mathrm{C}$ in $50 \mathrm{mM}$ phosphate buffer in a volume of $200 \mu \mathrm{l}$. The incubation conditions were optimized to ensure that M1 formation was linear with incubation time and protein concentration. The incubations were initiated with the addition of NADPH cofactor (final concentration of $1 \mathrm{mM}$ ). At the end of the incubation, the reaction mixtures were quenched with 2-fold volume of acetonitrile containing $50 \mathrm{nM}$ of carbutamide (internal standard) and centrifuged at $1811 \mathrm{~g}$ for 10 minutes. The supernatants and standards were analyzed by LC-MS/MS. Detailed analytical conditions are described in the LC-MS/MS Analysis for In Vitro Samples section.

Incubation in HLMs and HKMs and Thermal Inactivation Studies. To investigate more fully FMO contributions to the oxidative metabolism of ABT-126, incubations were conducted with HLMs or HKMs. An incubation mixture $(360 \mu \mathrm{l})$ contained $0.5 \mathrm{mg} / \mathrm{ml}$ HLMs or HKMs (untreated and thermally treated) and ABT-126 $(150 \mu \mathrm{M})$ in $50 \mathrm{mM}$ potassium phosphate buffer at $\mathrm{pH} 7.4$ and were conducted in triplicate. The reaction was initiated by the addition of $10 \mathrm{mM}$ of NADPH $(40 \mu \mathrm{l}$, final concentration of $1 \mathrm{mM})$ and incubated at $37^{\circ} \mathrm{C}$. After $0,15,30$, and 60 minutes, the reaction was terminated by transferring a $25-\mu \mathrm{l}$ aliquot of the incubation mixture into $125 \mu \mathrm{l}$ of acetonitrile containing $50 \mathrm{nM}$ carbutamide as internal standard. After vortexing and centrifugation, the 
supernatants were analyzed by HPLC. A standard curve of M1 was prepared under same conditions. Detailed analytical conditions are described in the Method for Metabolite Profiling and Identification section.

Thermal Inactivation of Microsomal FMO. The FMO enzyme(s) in HLMs or HKMs reagents was thermally inactivated according to the method of Grothusen et al. (1996). Suspensions of HLMs and HKMs (diluted to $0.56 \mathrm{mg} / \mathrm{ml}$ in $50 \mathrm{mM}$ phosphate buffer) were placed in a $50^{\circ} \mathrm{C}$ water bath. After 90 seconds, the tubes were immediately chilled in ice-cold water.

UGT Phenotyping and Kinetics. The in vitro glucuronidation of ABT-126 was investigated using a panel of recombinant human UGT enzymes (UGT1A1, 1A3, 1A4, 1A6, 1A7, 1A9, 1A10, 2B4, 2B7, 2B10, 2B15, and 2B17). An incubation mixture contained individual UGT at $1 \mathrm{mg} / \mathrm{ml}, \mathrm{ABT}-126(0.5-1 \mu \mathrm{M}), \mathrm{MgCl} 2[1$ or $10 \mathrm{mM}$ (UGT2B10 only)], and 50 or $5 \mu \mathrm{g} / \mathrm{ml}$ (UGT2B10 only) of alamethicin in $50 \mathrm{mM}$ Tris buffer at $\mathrm{pH}$ 7.4. The mixtures were kept at $0^{\circ} \mathrm{C}$ for 15 minutes to allow alamethicin to form membrane pores. The reaction was initiated by the addition of $5 \mathrm{mM}$ UDPGA and incubated at $37^{\circ} \mathrm{C}$ for 60 minutes. The reaction was terminated by addition of $2 \times$ volume of acetonitrile/methanol $(1 / 1, \mathrm{v} / \mathrm{v})$. After centrifugation, supernatants were analyzed by HPLC analysis with radiometric detection or LC-MS/MS detection (UGT2B10 only) as described earlier.

To determine enzyme kinetic parameters for the formation of M11, incubations containing ABT-126 at varying concentrations $(0.2-150 \mu \mathrm{M}$ for UGT1A4 and $0.5-50 \mu \mathrm{M}$ for UGT2B10) were conducted in triplicate with recombinant UGT1A4 $(0.1 \mathrm{mg} / \mathrm{ml}, 20$ minutes $)$ and UGT2B $10(0.15 \mathrm{mg} / \mathrm{ml}, 20$ minutes $)$ at $37^{\circ} \mathrm{C}$ in $50 \mathrm{mM}$ Tris buffer containing $5 \mathrm{mM}$ of UDPGA, $10 \mathrm{mM} \mathrm{MgCl}_{2}$, and $5 \mu \mathrm{g} / \mathrm{ml}$ of alamethicin. The total reaction volume was $80 \mu \mathrm{l}$. The incubation conditions were optimized to ensure that the formation of M11 was linear with incubation time and protein concentration. At the end of the incubations, the reaction mixtures were quenched with $160 \mu \mathrm{l}$ of acetonitrile containing $50 \mathrm{nM}$ of carbutamide (internal standard) and centrifuged at $1811 \mathrm{~g}$ for 15 minutes. The supernatants were analyzed by LC-MS/MS. Detailed analytical conditions are described in the LC-MS/MS Analysis for In Vitro Samples section.

Enzyme Kinetic Analysis. Enzyme kinetic analysis was performed using GraphPad Prism software. Data were fit to a one- or two-binding-site model based on visual inspection of Eadie-Hofstee plots indicating monophasic or biphasic kinetics, respectively. Goodness of fit was determined by Akaike information criterion and/or ensuring an even distribution of data points around the fitted line. Individual kinetic parameters were determined using eq. 1 (UGT2B10) or eq. 2 (UGT1A4):

$$
\begin{gathered}
v=\frac{V_{\max }[\mathrm{S}]}{K_{m}+[\mathrm{S}]} \\
v=\frac{V_{\max 1}[\mathrm{~S}]}{K_{m 1}+[\mathrm{S}]}+\frac{V_{\max 2}[\mathrm{~S}]}{K_{m 2}+[\mathrm{S}]}
\end{gathered}
$$

Kinetic parameters were used to obtain overall intrinsic clearance $\left(C L_{\text {int }}\right.$; microliters per minute per milligram).

\section{Results}

\section{Pharmacokinetics}

The PK parameters for ABT-126 and its metabolites and for total radioactivity are summarized in Table 1; the PK profiles are shown in
Fig. 1. The concentration of total radioactivity was measured by LSC, expressed in nanogram-equivalent per gram. The concentrations of ABT-126 were determined using a validated LC-MS/MS bioanalytical method (expressed in units of nanogram per milliliter) and a radioprofiling method (expressed in units of nanogram-equivalent per gram). The concentrations of M1 and M11 were determined using radioprofiling and expressed in units of nanogram-equivalent per gram. The concentrations of ABT-126 determined using a validated LC-MS/MS method were similar to those determined using radioprofiling. ABT-126 reached maximum plasma concentrations $\left(T_{\max }\right)$ at a median of 4 hours and had a mean $C_{\max }$ and $t_{1 / 2}$ (terminal phase elimination half-life) of $89.7 \mathrm{ng} / \mathrm{ml}$ and 33.9 hours, respectively. The maximal plasma concentrations of total radioactivity, M1, and M11 were achieved at 4, 3, and 16 hours postdose, respectively. The estimation of $t_{1 / 2}$ values for total radioactivity, ABT-126 (radioprofiling), M1, and M11 was not conducted owing to the absence of measurable radioactivity after 48 hours. M1 and M11 represented about $115 \%$ and $128 \%$ of parent drug exposure $\left(\mathrm{AUC}_{\infty}\right)$ and accounted for approximately $32.6 \%$ and $36.6 \%$ of plasma radioactivity (based on $\mathrm{AUC}_{\infty}$ ), respectively.

\section{Excretion of Radioactivity}

The mean cumulative percentage of the radioactive dose recovered in urine and feces is illustrated in Fig. 2. ABT-126 and related materials were excreted primarily in urine with a mean ( \pm S.D.) recovery of $81.5 \%$ $( \pm 10.2 \%)$ of the administered dose. Mean ( \pm S.D.) fecal excretion accounted for $12.4 \%( \pm 9.3 \%)$ of the administered dose. Total recovery of radioactivity in urine and feces was $94.0 \%( \pm 2.09 \%)$, with recovery in individual subjects ranging from $91.0 \%$ to $95.9 \%$. Most of the administered radioactivity was recovered in the first 120 hours postdose $(89.3 \%)$.

\section{Metabolite Profiles of $\left[{ }^{14} \mathrm{C}\right] \mathrm{ABT}-126$ in Circulation and Excreta}

Plasma. A representative HPLC radiochromatogram of $\left[{ }^{14} \mathrm{C}\right] \mathrm{ABT}$ 126 and its metabolites in pooled human plasma is shown in Fig. 3. ABT-126, M1 ( $N$-oxide), and M11 ( $N$-glucuronide) are predominant components in human plasma, and metabolite M12 ( $N$-glucose conjugate) is present as a minor metabolite. In addition, trace levels of metabolites M3 (dioxidation), M7 (dioxidation plus sulfation), M8 (mono-oxidation plus glucuronidation), M10 (mono-oxidation plus cysteine conjugation), and M16 ( $N$-oxidation plus glucuronidation) were detected only by LC-MS analysis.

Urine. The representative HPLC radiochromatogram of pooled human urine is shown in Fig. 4. The amount of ABT-126 and metabolites in urine, expressed as the mean percentage of the administered dose, is tabulated in Table 2. The administered $\left[{ }^{14} \mathrm{C}\right] \mathrm{ABT}-126$ was recovered primarily in urine as metabolites ( $74.6 \%$ of the administered dose), whereas $6.6 \%$ of

TABLE

\begin{tabular}{|c|c|c|c|c|c|c|c|}
\hline Pharmacokinetic Parameters $^{a}$ & $\begin{array}{c}T_{\max } \\
h\end{array}$ & $\begin{array}{c}C_{\max } \\
n g / m l \text { or } n g-e q / g\end{array}$ & $\begin{array}{c}\mathrm{AUC}_{(0-\mathrm{t})} \\
h \bullet n g / m l \text { or høng-eq/g }\end{array}$ & $\begin{array}{c}\mathrm{AUC}_{0-\infty} \\
h \bullet n g / m l \text { or } h \bullet n g-e q / g \text { ) }\end{array}$ & $\begin{array}{c}t_{1 / 2}{ }^{c} \\
h\end{array}$ & $\begin{array}{l}\% \text { Total Radioactivity } \\
\qquad A U C_{0-\infty}\end{array}$ & $\begin{array}{c}\% \text { of } \mathrm{ABT}-126 \\
A U C_{0-\infty}\end{array}$ \\
\hline ABT- $126^{a}$ (LC-MS/MS) & $4.0(1.6)$ & $89.7(15.2)$ & $2400(525)$ & $2440(532)$ & $33.9(5.1)$ & 26.2 & - \\
\hline ABT- $126^{b}$ (radioprofiling) & 4 & 101 & 2190 & 2620 & - & 28.5 & - \\
\hline $\mathrm{M}^{b}$ (radioprofiling) & 3 & 159 & 2260 & 3000 & - & 32.6 & 115 \\
\hline M11 $1^{b}$ (radioprofiling) & 16 & 72.9 & 2320 & 3360 & - & 36.6 & 128 \\
\hline Total radioactivity (LSC) (S.D.) ${ }^{a}$ & $4(1.4)$ & $318(19)$ & $7400(1406)$ & $9190(1746)$ & - & - & - \\
\hline
\end{tabular}

Mean (\%CV) PK parameters of total radioactivity, ABT-126, and its metabolites in plasma after a single oral dose of $\left[{ }^{14} \mathrm{C}\right] \mathrm{ABT}-126$

${ }^{a} n=4$

$n=4$.
${ }^{b}$ Pharmacokinetic parameters for ABT-126 and its metabolites were calculated from pooled samples (pooled per each time point across subjects so that one concentration per time point was obtained for parent and each metabolite).

${ }^{c}$ Terminal phase elimination half-life $t_{1 / 2}$ was not determined for total radioactivity, ABT-126 (radioprofiling), M1,and M11 because radioactivity levels were below LOQ (40.1 ng equivalents/g) in the samples from 72 to $192 \mathrm{~h}$. 


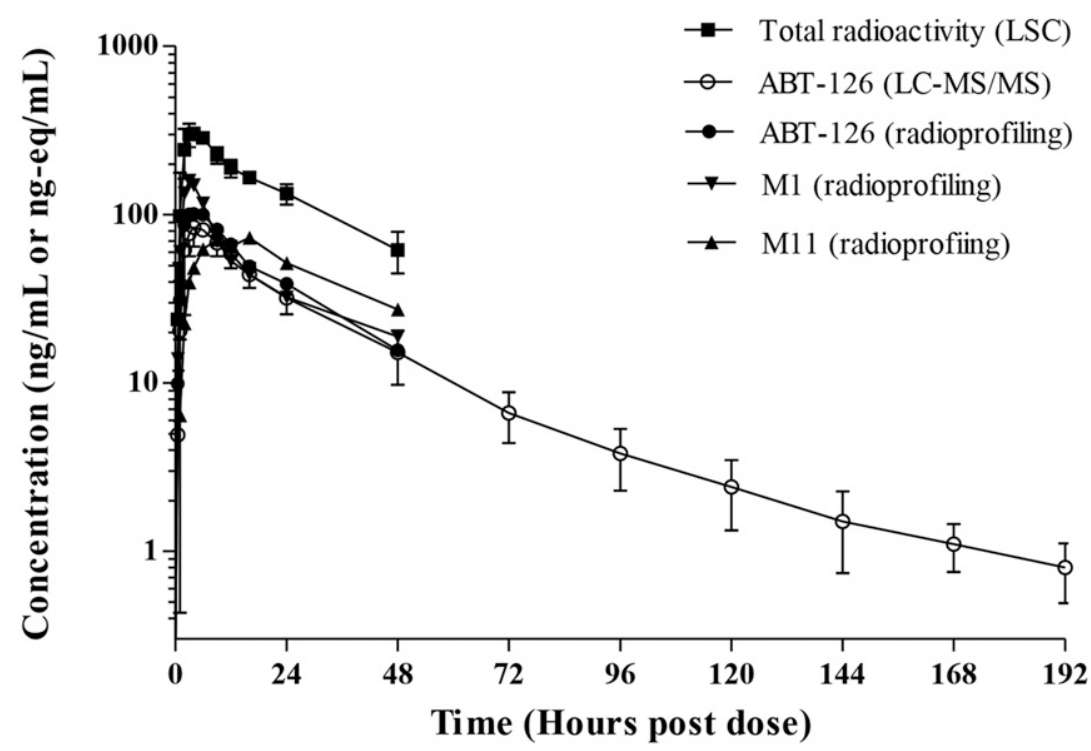

Fig. 1. Mean plasma concentration-time profiles of total radioactivity, ABT-126, M1, and M11 in healthy male subjects after a single oral dose of $100 \mathrm{mg}$ of $\left[{ }^{14} \mathrm{C}\right] \mathrm{ABT}-126$ containing $100 \mu \mathrm{Ci}$ radioactivity.

the administered dose was recovered as the unchanged parent drug. Similarly, with the metabolite profile in plasma, the most significant metabolites in urine were M1 and M11, representing 50.3\% and $19.9 \%$ of the administered dose, respectively. Several minor metabolites were also identified in urine, including M3, M10, M12, and M16, each representing $<2 \%$ of the administered dose. Trace amounts of metabolites, including M7 and M8, were detected only by LC/MS.

Feces. The representative HPLC radiochromatogram of pooled human feces is shown in Fig. 5. The amount of ABT-126 and metabolites in feces, expressed as the mean percentage of the administered dose, is tabulated in Table 2. The administered $\left[{ }^{14} \mathrm{C}\right] \mathrm{ABT}-126$ was recovered in feces, primarily as intact parent drug (12.2\% of the administered dose); $0.2 \%$ of the administered dose was recovered M11. Minor metabolites including M1, M3, and M12 were only detected by LC-MS analysis.

\section{Structural Characterization of ABT-126 and Main Metabolites}

The proposed metabolic pathways for ABT-126 in humans are shown in Fig. 6. Metabolites of ABT-126 were characterized using a combination of positive-ionization high-resolution full-scan MS and product ion scan (MS/MS) analyses (Figure S2). The chemical structures of metabolites M1, M11, and M12 were confirmed by comparing the chromatographic retention times and mass spectral fragmentations with those of the reference standards. Chemical structures of other minor metabolites (each $<2 \%$ of the dose), including M3, M7, M8, M10, and M16, were proposed based on high-resolution MS/MS fragmentation pattern analysis. The high-resolution product ion mass spectra and proposed structures for these minor metabolites are presented in Supplemental Fig. S2. The measured accurate masses and characteristic fragment ions are listed in Table 3.

ABT-126. ABT-126 yielded a protonated molecular ion at $\mathrm{m} / \mathrm{z}$ 314.1325 (calculated mass $m / z$ 314.1322; $\mathrm{C}_{17} \mathrm{H}_{20} \mathrm{~N}_{3} \mathrm{OS}^{+}$). Collisioninduced dissociation of ABT-126 ( $/ 2 / z 314)$ produced the fragment ions at $m / z 136.1122$ (loss of phenylthiadiazole moiety; $\mathrm{C}_{9} \mathrm{H}_{14} \mathrm{~N}^{+}$), $m / z$ 137.1199 (loss of phenylthiadiazole moiety; $\mathrm{C}_{9} \mathrm{H}_{15} \mathrm{~N}^{++}$), $\mathrm{m} / z 211.0897$ (loss of the phenylmethanimine moiety; $\mathrm{C}_{10} \mathrm{H}_{15} \mathrm{~N}_{2} \mathrm{OS}^{+}$), and $\mathrm{m} / \mathrm{z}$ 254.1649 (1, 3 rearrangement of ABT-126, followed by loss of $\mathrm{SCH}_{2} \mathrm{O}$;

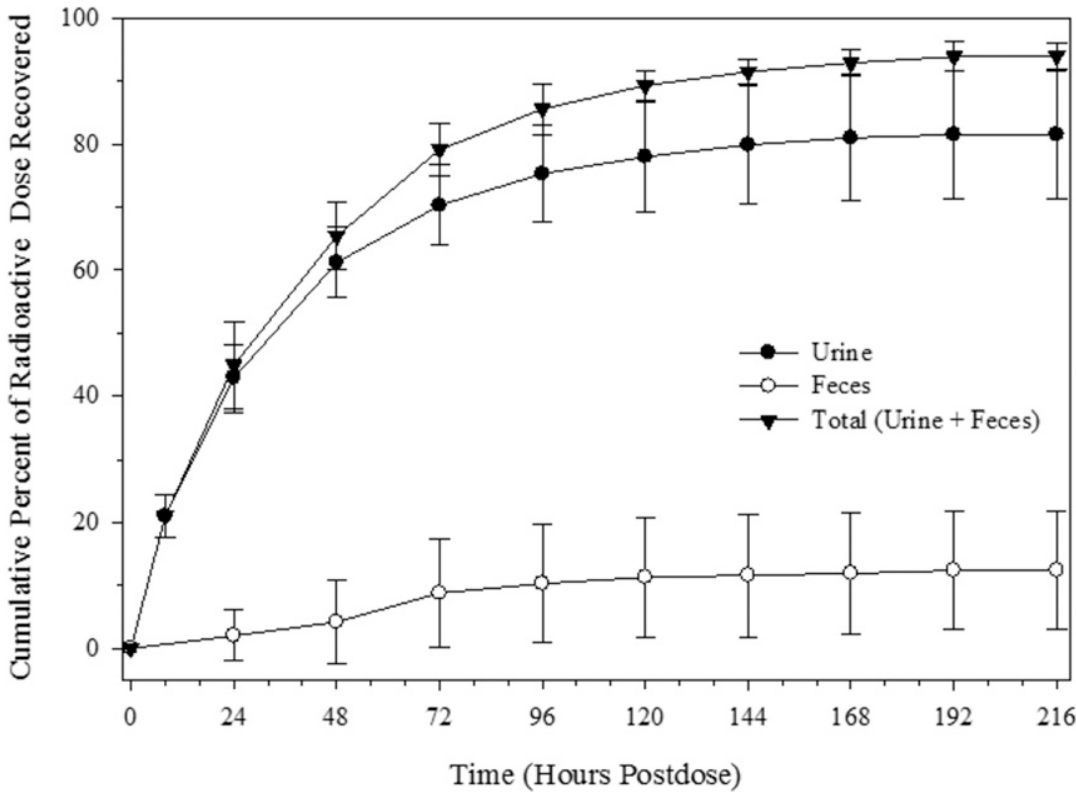

Fig. 2. Mean $( \pm$ S.D. $)$ cumulative percentage of radioactive dose recovered in urine and feces at specified intervals after a single oral dose of $100 \mathrm{mg}(100 \mu \mathrm{Ci})$ of $\left[{ }^{14} \mathrm{C}\right] \mathrm{ABT}-126$ to healthy male subjects. 


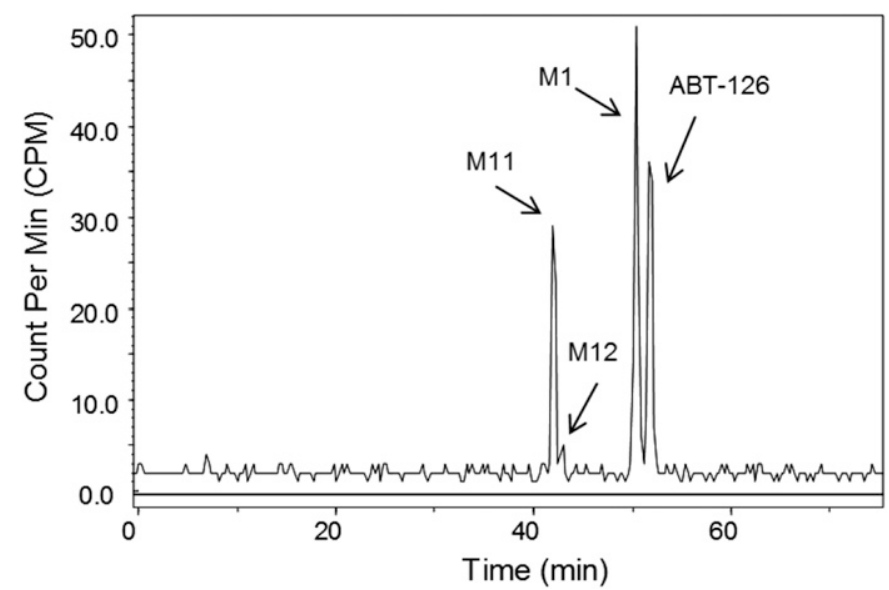

Fig. 3. Representative HPLC radiochromatogram of ABT-126 and its metabolites in human plasma at 6 hours after a single oral dose of $\left[{ }^{14} \mathrm{C}\right] \mathrm{ABT}-126$ to healthy male subjects.

$\mathrm{C}_{16} \mathrm{H}_{20} \mathrm{~N}_{3}^{+}$). Proposed fragmentation pathways of ABT-126 are provided in Supplemental Fig. 1.

M1. The metabolite M1 produced a protonated molecular ion at $\mathrm{m} / \mathrm{z}$ 330.1274 , indicating the addition of one oxygen atom to the parent drug (calculated mass $m / z$ 330.1271; $\mathrm{C}_{17} \mathrm{H}_{20} \mathrm{~N}_{3} \mathrm{O}_{2} \mathrm{~S}^{+}$). The collision-induced dissociation of $\mathrm{M} 1(\mathrm{~m} / \mathrm{z}, 330)$ produced the key fragment ions at $\mathrm{m} / \mathrm{z}$ 152.1071 (loss of phenylthiadiazole moiety) and $\mathrm{m} / \mathrm{z} 136.1122$ (further loss of oxygen from $\mathrm{m} / \mathrm{z}$ 152), suggesting that oxidation occurred at azaadamantane nitrogen. M1 was assigned as an $N$-oxide metabolite of ABT-126. The structure of M1 was further confirmed by comparing MS/MS fragmentation pattern and chromatographic retention time with the reference standard. Proposed fragmentation pathways of M1 are provided in Supplemental Fig. 1.

M11. The metabolite M11 produced a protonated molecular ion at $\mathrm{m} / \mathrm{z}$ 490.1642, suggesting the addition of a glucuronide to the parent drug (calculated mass $m / z$ 490.1643; $\mathrm{C}_{23} \mathrm{H}_{28} \mathrm{~N}_{3} \mathrm{O}_{7} \mathrm{~S}^{+}$). The major fragment of M11 was $m / z 314.1318$ (loss of glucuronide). M11 was assigned as a quaternary $\mathrm{N}$-glucuronide of ABT-126. The structure of M1 was further confirmed by comparing MS/MS fragmentation pattern and chromatographic retention time with the reference standard.

M12. The metabolite M12 produced a protonated molecular ion of $\mathrm{m} / \mathrm{z} 476.1848$, indicating the addition of a glucose to the parent drug
TABLE 2

Percentages of ABT-126 and metabolites in human urine and feces after a single oral dose of $100 \mathrm{mg}(100 \mu \mathrm{Ci})$ of $\left[{ }^{14} \mathrm{C}\right] \mathrm{ABT}-126(n=4)$

\begin{tabular}{lccc}
\hline Compounds & $\begin{array}{c}\text { Urine } \\
(0-192 \mathrm{~h})\end{array}$ & $\begin{array}{c}\text { Feces } \\
(0-192 \mathrm{~h})\end{array}$ & Total \\
\hline ABT-126 & 6.6 & 12.2 & 18.8 \\
M1 & 50.3 & MS & 50.3 \\
M3 & 0.9 & MS & 0.9 \\
M7 & MS & N.D. & N.A. \\
M8 & MS & N.D. & N.A. \\
M10 & 0.9 & N.D. & 0.9 \\
M11 & 19.9 & 0.2 & 20.1 \\
M12 & 1.5 & MS & 1.5 \\
M16 & 0.2 & N.D. & 0.2 \\
UNK1 & 0.9 & N.D. & 0.9 \\
\hline
\end{tabular}

MS, Detected in mass spectrometry only; N.A., not applicable; N.D., not detected.

(calculated mass $m / z$ 476.1850; $\mathrm{C}_{23} \mathrm{H}_{30} \mathrm{~N}_{3} \mathrm{O}_{6} \mathrm{~S}^{+}$). The major fragment of M12 was $\mathrm{m} / \mathrm{z}, 314.1317$ (loss of glucose). M12 was assigned as quaternary $\mathrm{N}$-glucose conjugate of ABT-126. The structure of M12 was further confirmed by comparing MS/MS fragmentation pattern and chromatographic retention time with the reference standard.

\section{Metabolite Profile from Hepatocyte Incubations}

After incubations of $\left[{ }^{3} \mathrm{H}\right] \mathrm{ABT}-126$ in rat, dog, monkey, and human hepatocytes ( $1 \mu \mathrm{M}, 0-4$ hours), ABT-126 showed highest intrinsic clearance in dog hepatocytes $(4.8 \mathrm{~L} / \mathrm{h} / \mathrm{kg})$. The intrinsic clearance was lower in human, monkey, and rat $(\sim 1.0 \mathrm{~L} / \mathrm{h} / \mathrm{kg})$ hepatocytes. M1 was the primary metabolite in the test species, representing $25.4 \%$ (human), $47.4 \%$ (monkey), $92.1 \%$, (dog), and $42.8 \%$ (rat) of total drug related material after 4-hour incubations, respectively. M11 was observed in human $(18.4 \%)$ and monkey $(9.4 \%)$ hepatocytes but not in dog and rat hepatocytes. In addition, a trace amount of M12 was detected only in human hepatocyte incubations by LC-MS.

\section{Metabolism of ABT-126 with cDNA-Expressed Cytochrome 450 and FMO Enzymes}

Incubations of $\left[{ }^{3} \mathrm{H}\right] \mathrm{ABT}-126$ with human cDNA-expressed $\mathrm{P} 450$ (CYP1A2, 2A6, 2B6, 2C8, 2C9, 2C18, 2C19, 2D6, 2E1, 3A4) or FMO enzymes (FMO1, FMO3, and FMO5) at $37^{\circ} \mathrm{C}$ for 60 minutes indicated that several enzymes were capable of metabolizing ABT-126 to form

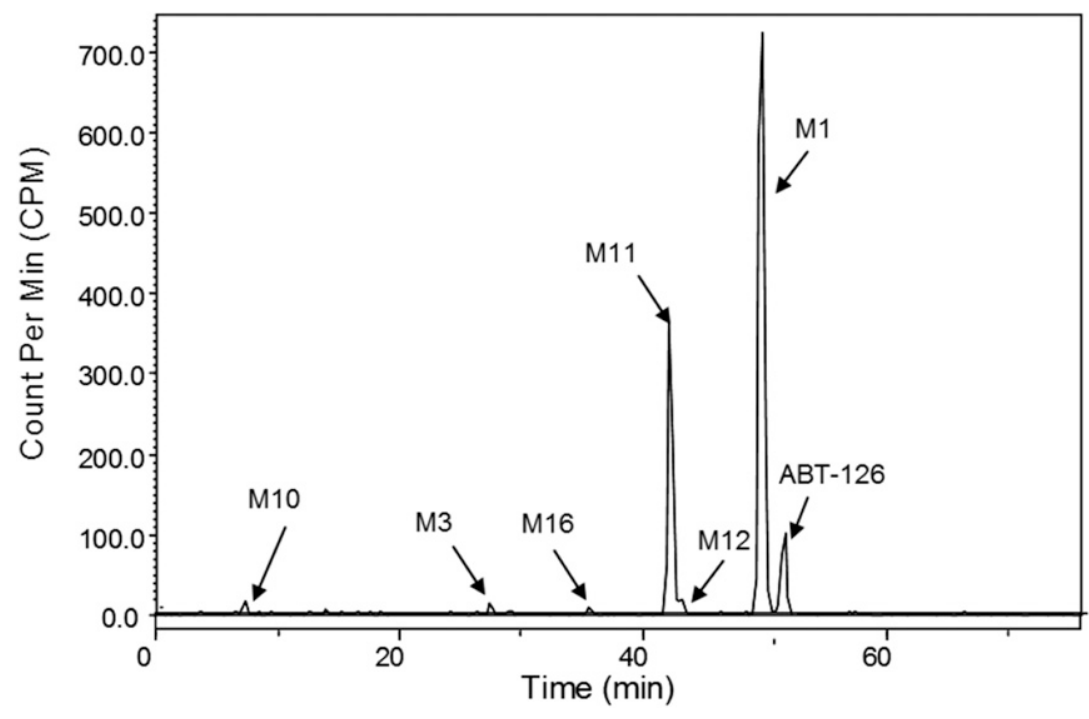

Fig. 4. Representative HPLC radiochromatogram of ABT-126 and its metabolites in human urine after a single oral dose of $\left[{ }^{14} \mathrm{C}\right] 126$ (24-48 hours postdose). 


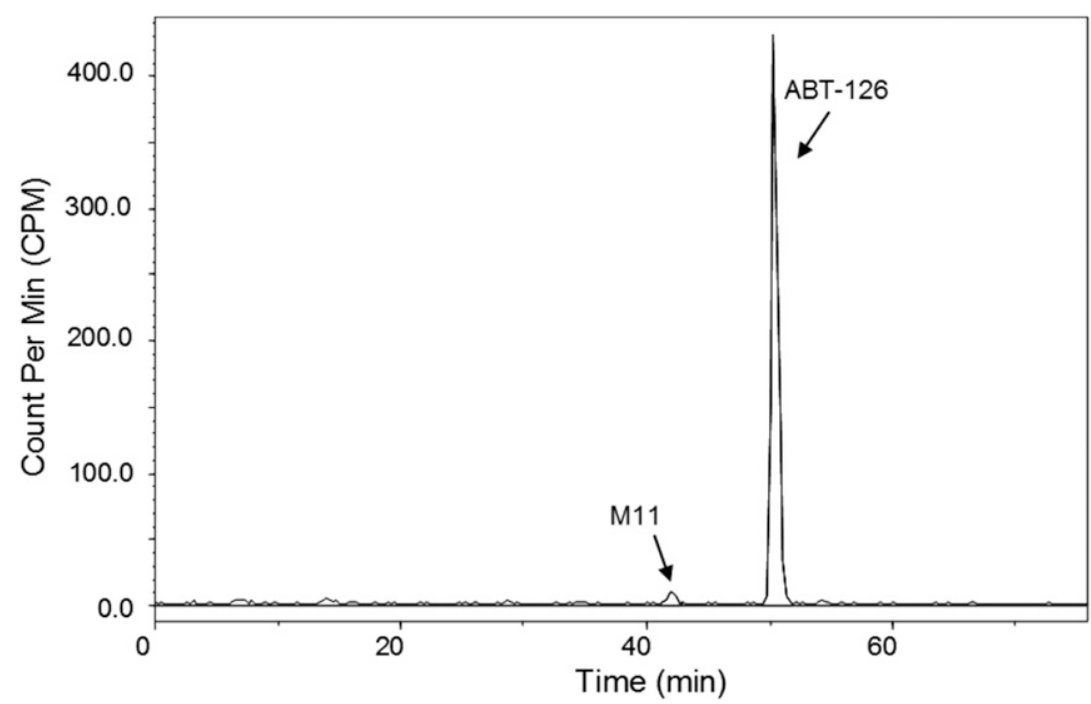

Fig. 5. Representative HPLC radiochromatogram of ABT-126 and its metabolites in human feces after a single oral dose of $\left[{ }^{14} \mathrm{C}\right] \mathrm{ABT}-126$ (8-24 hours postdose).

M1. These enzymes included CYP3A4 (10\% conversion to M1), 2D6 ( $2.1 \%$ conversion to M1), 2B6 (3.2\% conversion to M1), FMO1(100\% conversion to M1), and FMO3 (100\% conversion to M1). Kinetic studies (Fig. 7) were conducted to determine the $K_{\mathrm{m}}$ and $V_{\max }$ values for
M1 formation with cDNA-expressed FMO1 and FMO3. M1 formation catalyzed by FMO1 and FMO3 exhibited Michaelis-Menten kinetics with apparent $K_{\mathrm{m}}$ values of 12.5 and $89.4 \mu \mathrm{M}, V_{\max }$ values of $2610 \mathrm{pmol} / \mathrm{min}$ per milligram protein and $2870 \mathrm{pmol} / \mathrm{min}$ per milligram

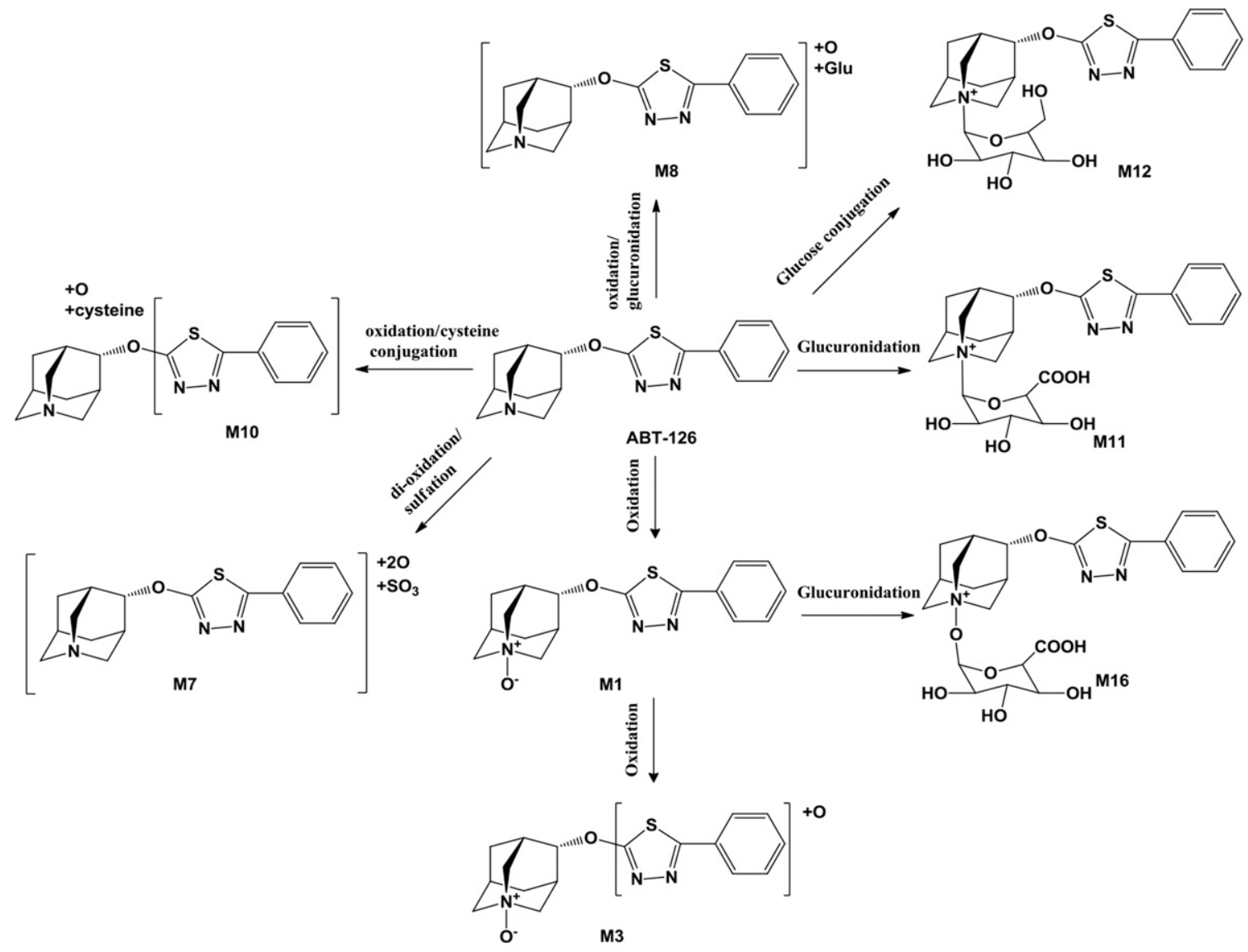

Metabolites including M3, M7, M8, M10, M12, M16 are minor metabolites (each $<2 \%$ of dose).

Fig. 6. Proposed metabolic pathways of ABT-126 in humans. 
TABLE 3

Molecular ions and characteristic fragment ions of ABT-126 and metabolites in human plasma, feces, and/or urine

\begin{tabular}{lccrll}
\hline Compound & {$[\mathrm{M}+\mathrm{H}]^{+}$(Theoretical) } & {$[\mathrm{M}+\mathrm{H}]^{+}$(Measured) } & $\Delta$ ppm & Molecular Formula & \multicolumn{1}{c}{ Key Fragment Ions $(\mathrm{m} / \mathrm{z})$} \\
\hline ABT-126 & 314.1322 & 314.1325 & 0.9 & $\mathrm{C}_{17} \mathrm{H}_{20} \mathrm{~N}_{3} \mathrm{OS}^{+}$ & $254,211,137,136,108$ \\
M1 & 330.1271 & 330.1274 & 0.9 & $\mathrm{C}_{17} \mathrm{H}_{20} \mathrm{~N}_{3} \mathrm{O}_{2} \mathrm{~S}^{+}$ & $313,270,227,152,136$ \\
M3 & 346.1220 & 346.1220 & -0.1 & $\mathrm{C}_{17} \mathrm{H}_{20} \mathrm{~N}_{3} \mathrm{O}_{3} \mathrm{~S}^{+}$ & $329,152,136$ \\
M7 & 426.0788 & 426.0786 & -0.5 & $\mathrm{C}_{17} \mathrm{H}_{20} \mathrm{~N}_{3} \mathrm{O}_{6} \mathrm{~S}_{2}^{+}$ & 346 \\
M8 & 506.1592 & 506.1591 & -0.2 & $\mathrm{C}_{23} \mathrm{H}_{28} \mathrm{~N}_{3} \mathrm{O}_{8} \mathrm{~S}^{+}$ & 330 \\
M10 & 451.1468 & 451.1467 & -0.2 & $\mathrm{C}_{20} \mathrm{H}_{27} \mathrm{~N}_{4} \mathrm{O}_{4} \mathrm{~S}_{2}^{+}$ & $433,364,330,314,136$ \\
M11 & 490.1643 & 490.1642 & -0.2 & $\mathrm{C}_{23} \mathrm{H}_{28} \mathrm{~N}_{3} \mathrm{O}_{7} \mathrm{~S}^{+}$ & 314 \\
M12 & 476.1850 & 476.1848 & -0.4 & $\mathrm{C}_{23} \mathrm{H}_{30} \mathrm{~N}_{3} \mathrm{O}_{6} \mathrm{~S}^{+}$ & 314 \\
M16 & 506.1592 & 506.1592 & 0 & $\mathrm{C}_{23} \mathrm{H}_{28} \mathrm{~N}_{3} \mathrm{O}_{8} \mathrm{~S}^{+}$ & 330,314 \\
\hline
\end{tabular}

protein, and $\mathrm{CL}_{\text {int }}$ values of 0.21 and $0.032 \mathrm{ml} / \mathrm{min}$ per milligram, respectively (Table 4 ).

\section{Metabolism of ABT-126 with cDNA-Expressed UGT Enzymes}

A panel of recombinant UGT enzymes (UGT1A1, 1A3, 1A4, 1A6, $1 \mathrm{~A} 7,1 \mathrm{~A} 9,1 \mathrm{~A} 10,2 \mathrm{~B} 4,2 \mathrm{~B} 7,2 \mathrm{~B} 10,2 \mathrm{~B} 15$, and 2B17) was incubated with $\left.{ }^{3} \mathrm{H}\right] \mathrm{ABT}-126\left(37^{\circ} \mathrm{C}\right.$ for 60 minutes $)$. Parent turnover was observed only with UGT1A4 and UGT2B10 only. Follow-on kinetic studies were conducted to determine the $K_{\mathrm{m}}$ and $V_{\max }$ values for M11 formation with these two enzymes. Biphasic kinetics was observed for M11 formation by UGT1A4 (Fig. 8). The high-affinity component exhibited apparent $K_{\mathrm{m}}, V_{\max }$, and $C L_{\text {int }}$ values of $0.232 \mu \mathrm{M}, 0.613 \mathrm{pmol} / \mathrm{min}$ per milligram, and $0.0026 \mu \mathrm{l} / \mathrm{min}$ per milligram, respectively, whereas the low-affinity component showed apparent $K_{\mathrm{m}}, V_{\mathrm{max}}$, and $C L_{\mathrm{int}}$ values of $115 \mu \mathrm{M}$, $123 \mathrm{pmol} / \mathrm{min}$ per milligram, and $0.0011 \mu \mathrm{l} / \mathrm{min}$ per milligram, respectively (Table 4). M11 formation by UGT2B10 best fit to one-enzyme Michaelis-Menten kinetics, with an apparent $K_{\mathrm{m}}, V_{\max }$, and $C L_{\text {int }}$ values of $0.504 \mu \mathrm{M}, 0.17 \mathrm{pmol} / \mathrm{min}$ per milligram, and $0.00034 \mu \mathrm{l} / \mathrm{min}$ per milligram protein, respectively (Table 4 ).

\section{Metabolism of ABT-126 After Thermal Treatment of HKMs and HLMs}

Expression of FMO3 and FMO5 is dominant in HLMs, whereas FMO1 is absent. In contrast, HKMs are rich in FMO1, but not other FMO isoforms (Phillips and Shephard, 2017). Therefore, it was of interest to 1) confirm metabolism to M1 $N$-oxide metabolite in these tissue preparations and 2) inhibit M1 formation by mild heat treatment, a process known to inactivate FMO, but not P450 (Grothusen et al., 1996). As anticipated, we observed robust formation of M1 N-oxide formation in both HLMs and HKMs and that the rate of M1 N-oxide formation declined substantially ( $\sim 80 \%$, Table 5$)$ upon heat treatment. Benzydamine, a known substrate of FMO1 and FMO3, was used as a positive control and gave the expected response with and without heat treatment (Supplemental Table 1) (Taniguchi-Takizawa et al, 2015). The presence of small but detectable M1 in 0-minute incubations is probably indicative of a small amount of M1 impurity in the starting substrate.

\section{Discussion}

After oral administration of $\left[{ }^{14} \mathrm{C}\right] \mathrm{ABT}-126$ in healthy subjects, mean total recovery was $94.0 \%( \pm 2.09 \%)$ over the 216 hours postdose. A mean of $81.5 \%( \pm 10.2 \%)$ of administered radioactivity was excreted in urine, indicating good oral absorption of ABT-126. ABT-126 was cleared by metabolism and renal excretion ( $90 \%$ and $10 \%$, respectively), with an oral clearance of $42.8(\mathrm{~L} / \mathrm{h})$. Oral bioavailability for ABT-126 in humans was $50 \%$, estimated based on the observed oral bioavailability in rats, dogs, and monkeys. Thus, the total plasma, renal, and metabolic clearance values were estimated to be 21,2 , and $19 \mathrm{~L} / \mathrm{h}$, respectively. The renal clearance of $2 \mathrm{~L} / \mathrm{h}$ indicates that renal elimination of ABT-126 is mainly via glomerular filtration (fraction unbound fu* glomerular filtration rate $=2.3 \mathrm{~L} / \mathrm{h}$, where $\mathrm{fu}=0.3$ and glomerular filtration rate $=$ $125 \mathrm{ml} / \mathrm{min}$ ). The primary metabolic transformations of ABT-126 include aza-adamantane $\mathrm{N}$-oxidation (M1, 50.3\% in urine) and azaadamantane $N$-glucuronidation (M11, 19.9\% in urine). M1 and M11 were major circulating components, representing $32.6 \%$ and $36.6 \%$ of
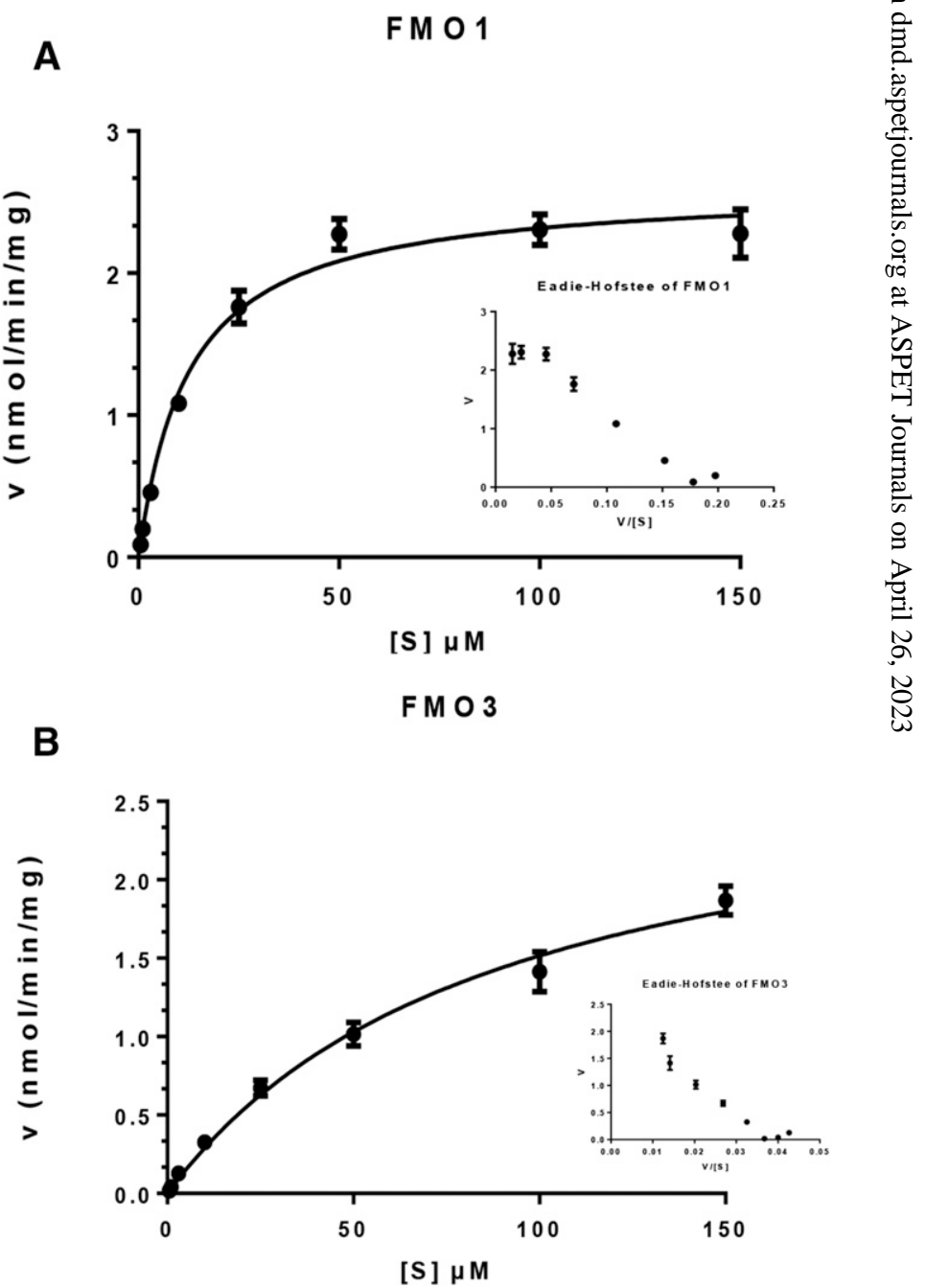

Fig. 7. Kinetic analysis of M1 formation by recombinant FMO1 (A) and FMO3 (B). The rates represent the mean $( \pm$ S.D.) of triplicate incubations. An Eadie-Hofstee plot is also presented as an inset for each enzyme. 
TABLE 4

Apparent kinetic parameters for $N$-oxidation of ABT-126 by recombinant FMO1 and FMO3 and $N$-glucuronidation of ABT-126 by recombinant UGT1A4 and UGT2B $10^{a}$

\begin{tabular}{lcccccc}
\hline & $K_{\mathrm{m}}$ & $V_{\max }$ & $\mathrm{CL}_{\mathrm{int}}$ & $K_{\mathrm{m} 2}$ & $\mathrm{~V}_{\max 2}$ & $\mathrm{CL}_{\mathrm{int} 2}$ \\
\hline \multirow{2}{*}{ FMO1 } & $\mu M$ & pmol/min per $m g$ & ml/min per $m g$ & $\mu M$ & pmol/min per mg & $\mu l / m i n ~ p e r ~ m g$ \\
& $12.5(1.8)$ & $2610(94)$ & 0.21 & N.A. & N.A. & N.A. \\
FMO3 & $89.4(15)$ & $2870(239)$ & 0.032 & N.A. & N.A. & N.A. \\
UGT1A4 & $0.232(0.044)$ & $0.613(0.068)$ & 0.0026 & $115(13)$ & $123(12)$ & 0.0011 \\
UGT2B10 & $0.504(0.041)$ & $0.17(0.003)$ & 0.00034 & N.A. & N.A. & N.A. \\
\hline
\end{tabular}

N.A., not applicable.

${ }^{a}$ Parameter estimates were obtained from data fitted on the mean of triplicate incubations; the S.E. of the estimate is shown in parenthesis for $K_{\mathrm{m}}$ and $V_{\max }$ parameters.

total plasma radioactivity ( $0-48$ hours), which was consistent with the $\sim 3$-fold higher plasma concentrations of total radioactivity compared with those of ABT-126 (measured by LC-MS/MS). The scaled in vitro intrinsic clearance from human hepatocytes $(22 \mathrm{~L} / \mathrm{h})$ was similar to the estimated in vivo metabolic clearance $(19 \mathrm{l} / \mathrm{h})$ noted earlier. These data suggest that metabolic clearance of ABT-126 is primarily mediated by hepatic enzymes.

$\mathrm{N}$-oxidation is a commonly observed metabolic pathway catalyzed by FMO, but also by P450 enzymes. Example tertiary amines undergoing $\mathrm{N}$-oxidation by FMO include tamoxifen, cimetidine, clozapine, itopride, and imipramine (Phillips and Shephard, 2017). Compared with P450s, FMOs exhibit a preference for substrates exhibiting greater nucleophilicity or basicity (Phillips and Shephard, 2017). ABT-126 contains a nucleophilic and basic nitrogen with a pKa value of 9 , consistent with our findings that M1 is formed primarily by cDNA-expressed FMO1 and FMO3, with only a minor contribution from CYP3A4 and 2D6. Our studies demonstrating $N$-oxidation in HLMs and HKMs, and that these catalytic activities could be suppressed by mild heat inactivation further confirm roles for FMO3 and FMO1 in ABT-126 metabolism. Additionally, the absence of significant CYP3A4 involvement was confirmed by a clinical drug-drug interactions study with ketoconazole showing that ABT-126 exposures $(75 \mathrm{mg}$ ) were not affected by ketoconazole (200 mg BID) (AbbVie internal data). Kinetic studies showed $V_{\max }$ values for M1 formation by cDNA-expressed FMO1 and FMO3 were comparable, but FMO1 exhibited approximately 7-fold higher affinity and intrinsic clearance as compared with FMO3. FMO1 is the most prevalent FMO in human kidney but absent in adult human liver, whereas FMO3 is the predominant FMO isoform in human liver (Cashman and Zhang, 2006). Despite FMO1 exhibiting high abundance of in kidney, after estimating expression and controlling for tissue weight, it has been estimated that the overall abundance of FMO1 is approximately 33-fold less than FMO3 (Overby et al., 1997; Yeung et al., 2000; Zhang and Cashman, 2006). Despite the observation of higher catalytic efficiency of FMO1 toward ABT-126, the significantly lower abundance of this enzyme compared with FMO3 suggests that M1 is generated primarily by human FMO3 after oral administration. Unfortunately, quantitative contribution of FMO1 and FMO3 to M1 formation and overall ABT-126 clearance is uncertain because of the lack of scaling factors or well established methods to extrapolate in vitro data to clinical observations. Recent progress using hepatocytes and heat deactivated or chemically inhibited HLMs is encouraging (Jones et al., 2017). Further studies are warranted to determine the inter-system extrapolation factor values for cDNA-expressed FMO1 and FMO3 to extrapolate activity from these recombinant systems to the activity present in HLMs or HKMs.

From the perspective of mitigating the potential for drug-drug interactions, significant contribution of FMO enzymes to the metabolism of ABT-126 is considered attractive. This is because FMO is not readily induced or inhibited by environmental chemicals or drugs (Cashman and
Zhang, 2006); therefore, ABT-126 clearance is unlikely to be affected by comedications. Similarly, significant drug-drug interactions arising with substrates of UGT enzymes are unlikely (Williams et al., 2004); therefore, the role of UGTs in ABT-126 metabolism is likely to reduce potential drug-drug interaction liabilities further.

The formation of the other major human metabolite aza-adamantane $N$-glucuronide (M11) was mediated by UGT1A4 and UGT2B10. UGT1A4 has been known to catalyze quaternary $N$-glucuronidation of substrates incorporating aliphatic tertiary amine or aromatic $\mathrm{N}$-heterocyclic group, including tricyclic antidepressants (TCAs), nicotine, nitrosamines (Green et al., 1995; Green and Tephly, 1998;

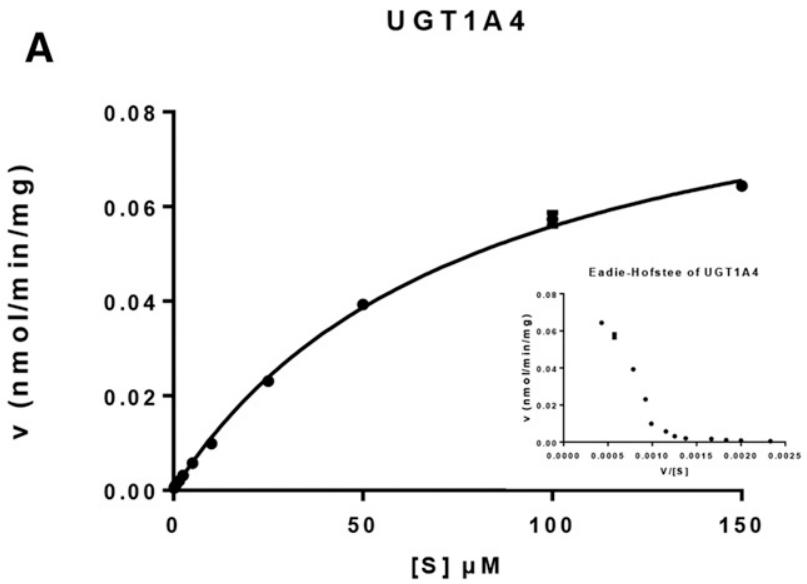

B U G T 2 B 10

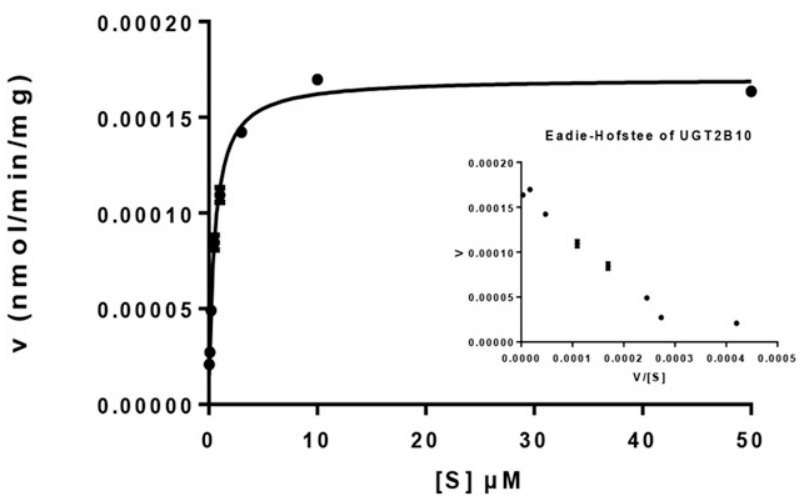

Fig. 8. Kinetic analysis of M11 formation of recombinant UGT1A4 (A) and UGT2B10 (B). The rates represent the mean ( \pm S.D.) of triplicate incubations. An Eadie-Hofstee plot is also presented as an inset for each enzyme. 
TABLE 5

Inactivation of M1 formation by thermal treatment of HLMs and HKMs

\begin{tabular}{llcrrr}
\hline \multicolumn{5}{c}{ M1 Metabolite Formation $(\mu \mathrm{M})$} \\
\hline HLMs & Substrate & 0 min & 15 min & 30 min & $60 \mathrm{~min}$ \\
HLMs + heat ${ }^{b}$ & ABT-126 & $0.071(0.016)^{a}$ & $1.5(0.068)$ & $3.0(0.023)$ & $7.6(1.1)$ \\
HKMs & ABT-126 & $0.056(0.003)$ & $0.33(0.008)$ & $0.63(0.012)$ & $1.5(0.071)$ \\
HKMs + heat & ABT-126 & $0.11(0.012)$ & $1.6(0.15)$ & $2.8(0.064)$ & $5.6(0.61)$ \\
& ABT-126 & $0.045(0.013)$ & $0.16(0.028)$ & $0.22(0.011)$ & $1.3(0.49)$ \\
\hline
\end{tabular}

${ }^{a}$ Mean (S.D.) of three replicates.

${ }^{b}$ Thermal treatment consisted of heating microsomal suspension for 90 seconds at $50^{\circ} \mathrm{C}$ before inclusion in the assay.

Kubota et al., 2007). Recent studies have indicated that UGT2B10 may also play an important role in catalyzing quaternary $\mathrm{N}$-glucuronidation reactions (Zhou et al., 2010; Fowler et al., 2015; Pattanawongsa et al., 2016) and often displays a lower $K_{\mathrm{m}}$ than UGT1A4. In the present study, UGT1A4 exhibited approximately 11-fold higher intrinsic clearance than UGT2B10 for M11 formation. Because hepatic abundance of UGT1A4 and UGT2B10 in human liver is similar (Sato et al., 2014), the higher intrinsic clearance exhibited by UGT1A4 suggests that M11 is generated mainly by human UGT1A4 with a lesser role for UGT2B10.

Notable species-dependent formation of M11 was observed in hepatocytes. After a 4-hour incubation, M11 was formed in humans (18.4\%) and monkeys (9.4\%) but not in dog or rat hepatocytes. Quaternary $N$-glucuronidation is commonly observed in human and nonhuman primates, but it is usually absent or minimal in rodents and dogs, which is consistent with our observations (Chiu and Huskey, 1998). Indeed, UGT1A4 is a nonfunctional pseudogene in rats and mice that may explain the low activities in rodents (Mackenzie et al., 2005). An ortholog of UGT2B10 has not yet been characterized in preclinical species, suggesting that UGT2B10 plays an important role in the $\mathrm{N}$ glucuronidation reactions in human and nonhuman primates only (Kaivosaari et al., 2011).

It is interesting to note that $\mathrm{N}$-oxidation and/or $\mathrm{N}$-glucuronidation reactions observed with $\mathrm{ABT}-126$ were similar to those observed for other $\alpha 7 \mathrm{nAChR}$ agonists that contain a quinuclidine ring (similar to aza-adamantane ring), including PHA-568487 (Shilliday et al., 2010), AZD0328, and N-(3R)-1-azabiocycl[2.2.2] ot-3-ylfuro[2,3-c]pyridine-5-carboxamide (1) (Shaffer et al., 2007) and ABT-107 (Liu et al., 2013).

M1 and M11 are not expected to be pharmacologically active in vivo in human as both metabolites exhibited essentially no in vitro activation of human $\alpha 7 \mathrm{nAChR}$ ( $>50$-fold less potent than ABT-126) at concentrations up to $100 \mu \mathrm{M}$ and no activation or inhibition of human $\alpha 4 \beta 2$ or activation of $\alpha 3 \beta 4$. Furthermore, M1 and M11 were evaluated in an extensive receptor binding panel that included G-protein-coupled receptors, ion channels, transporters, and are not expected to have clinically relevant off-target pharmacologic activity. In addition, the plasma quantification of M1 at steady state in human (100 mg, daily) and in rats, dogs, and monkeys at no-observedadverse-effects-level doses showed adequate coverage of M1 in these preclinical safety species.

In summary, this study with $\left[{ }^{14} \mathrm{C}\right] \mathrm{ABT}-126$ in healthy adult subjects showed that ABT-126 exhibits high absorption $(>81.5 \%$ of the administered dose), extensive metabolism, and was excreted renally ( $94 \%$ of the administered dose). ABT-126 was cleared predominantly by metabolism through aza-adamantane $N$-oxidation (M1) and azaadamantane $N$-glucuronidation (M11). M1 formation is catalyzed by human liver FMO3 and, to a lesser extent, by human kidney FMO1, whereas M11 formation is attributed to UGT1A4 with a minor role for UGT2B10.

\section{Authorship Contributions}

Participated in research design: Liu, Stresser, Othman.

Conducted experiments: Michmerhuizen, Li.

Contributed new reagents or analytic tools: Reed, Schrimpf.

Performed data analysis: Liu, Michmerhuizen, Stresser, Li, Othman.

Wrote or contributed to the writing of the manuscript: Liu, Stresser, Li, Michmerhuizen, Lee, Sydor.

\section{References}

Alzheimer's Association (2016) 2016 Alzheimer's disease facts and figures. Alzheimers Dement 12:459-509.

Cashman JR and Zhang J (2006) Human flavin-containing monooxygenases. Annu Rev Pharmacol Toxicol 46:65-100.

Chiu SH and Huskey SW (1998) Species differences in N-glucuronidation. Drug Metab Dispos 26: $838-847$.

Deardorff WJ, Shobassy A, and Grossberg GT (2015) Safety and clinical effects of EVP-6124 in subjects with Alzheimer's disease currently or previously receiving an acetylcholinesterase inhibitor medication. Expert Rev Neurother 15:7-17.

Florian H, Meier A, Gauthier S, Lipschitz S, Lin Y, Tang Q, Othman AA, Robieson WZ, and Gault LM (2016) Efficacy and safety of ABT-126 in subjects with mild-to-moderate Alzheimer's disease on stable doses of acetylcholinesterase inhibitors: a randomized, double-blind, placebocontrolled study. J Alzheimers Dis 51:1237-1247.

Fowler S, Kletzl H, Finel M, Manevski N, Schmid P, Tuerck D, Norcross RD, Hoener MC, Spleiss $\mathrm{O}$, and Iglesias VA (2015) A UGT2B10 splicing polymorphism common in african populations may greatly increase drug exposure. J Pharmacol Exp Ther 352:358-367.

Gault LM, Lenz RA, Ritchie CW, Meier A, Othman AA, Tang Q, Berry S, Pritchett Y, and Robieson WZ (2016) ABT-126 monotherapy in mild-to-moderate Alzheimer's dementia randomized double-blind, placebo and active controlled adaptive trial and open-label extension. Alzheimers Res Ther 8:44.

Gault LM, Ritchie CW, Robieson WZ, Pritchett Y, Othman AA, and Lenz RA (2015) A phase 2 randomized, controlled trial of the $\alpha 7$ agonist ABT-126 in mild-to-moderate Alzheimer's dementia. Alzheimers Dement Transl Res Clin Interv 1:81-90.

Gotti C and Clementi F (2004) Neuronal nicotinic receptors: from structure to pathology. Prog Neurobiol 74:363-396.

Green MD, Bishop WP, and Tephly TR (1995) Expressed human UGT1.4 protein catalyzes the formation of quaternary ammonium-linked glucuronides. Drug Metab Dispos 23:299-302.

Green MD and Tephly TR (1998) Glucuronidation of amine substrates by purified and expressed UDP-glucuronosyltransferase proteins. Drug Metab Dispos 26:860-867.

Grothusen A, Hardt J, Bräutigam L, Lang D, and Böcker R (1996) A convenient method to discriminate between cytochrome $\mathrm{P} 450$ enzymes and flavin-containing monooxygenases in human liver microsomes. Arch Toxicol 71:64-71.

Haig G, Wang D, Othman AA, and Zhao J (2016a) The alpha7 nicotinic agonist ABT-126 in the treatment of cognitive impairment associated with schizophrenia in nonsmokers: results from a randomized controlled phase 2b study. Neuropsychopharmacology 41:2893-2902.

Haig GM, Bain EE, Robieson WZ, Baker JD, and Othman AA (2016b) A randomized trial to assess the efficacy and safety of ABT-126, a selective $\alpha 7$ nicotinic acetylcholine receptor agonist, in the treatment of cognitive impairment in schizophrenia. Am J Psychiatry 173:827-835.

Hamilton RA, Garnett WR, and Kline BJ (1981) Determination of mean valproic acid serum level by assay of a single pooled sample. Clin Pharmacol Ther 29:408-413.

Jones BC, Srivastava A, Colclough N, Wilson J, Reddy VP, Amberntsson S, and Li D (2017) An investigation into the prediction of in vivo clearance for a range of Flavin-containing monooxygenase substrates. Drug Metab Dispos 45:1060-1067.

Kaivosaari S, Finel M, and Koskinen M (2011) N-glucuronidation of drugs and other xenobiotics by human and animal UDP-glucuronosyltransferases. Xenobiotica 41:652-669.

Kubota T, Lewis BC, Elliot DJ, Mackenzie PI, and Miners JO (2007) Critical roles of residues 36 and 40 in the phenol and tertiary amine aglycone substrate selectivities of UDP-glucuronosyltransferases $1 \mathrm{~A} 3$ and 1A4. Mol Pharmacol 72:1054-1062.

Lendvai B, Kassai F, Szájli A, and Némethy Z (2013) $\alpha 7$ nicotinic acetylcholine receptors and their role in cognition. Brain Res Bull 93:86-96.

Liu H, Deng X, Liu J, Liu N, Stuart P, Xu H, Guan Z, Marsh KC, and De Morais SM (2013) Species-dependent metabolism of a novel selective $\alpha 7$ neuronal acetylcholine receptor agonist ABT-107. Xenobiotica 43:803-816.

Mackenzie PI, Bock KW, Burchell B, Guillemette C, Ikushiro S, Iyanagi T, Miners JO, Owens IS, and Nebert DW (2005) Nomenclature update for the mammalian UDP glycosyltransferase (UGT) gene superfamily. Pharmacogenet Genomics 15:677-685.

Overby LH, Carver GC, and Philpot RM (1997) Quantitation and kinetic properties of hepatic microsoma and recombinant flavin-containing monooxygenases 3 and 5 from humans. Chem Biol Interact 106:29-45. Pattanawongsa A, Nair PC, Rowland A, and Miners JO (2016) Human UDPglucuronosyltransferase (UGT) 2B10: validation of cotinine as a selective probe substrate, 
inhibition by UGT enzyme-selective inhibitors and antidepressant and antipsychotic drugs, and structural determinants of enzyme inhibition. Drug Metab Dispos 44:378-388.

Phillips IR and Shephard EA (2017) Drug metabolism by flavin-containing monooxygenases of human and mouse. Expert Opin Drug Metab Toxicol 13:167-181.

Roncarati R, Scali C, Comery TA, Grauer SM, Aschmi S, Bothmann H, Jow B, Kowal D, Gianfriddo M, Kelley C, et al. (2009) Procognitive and neuroprotective activity of a novel alpha7 nicotinic acetylcholine receptor agonist for treatment of neurodegenerative and cognitive disorders. J Pharmacol Exp Ther 329:459-468.

Sato Y, Nagata M, Tetsuka K, Tamura K, Miyashita A, Kawamura A, and Usui T (2014) Optimized methods for targeted peptide-based quantification of human uridine $5^{\prime}$-diphosphateglucuronosyltransferases in biological specimens using liquid chromatography-tandem mass spectrometry. Drug Metab Dispos 42:885-889.

Shaffer CL, Gunduz M, Scialis RJ, and Fang AF (2007) Metabolism and disposition of a selective alpha(7) nicotinic acetylcholine receptor agonist in humans. Drug Metab Dispos 35:1188-1195

Shilliday FB, Walker DP, Gu C, Fang X, Thornburgh B, Fate GD, and Daniels JS (2010) Multiple species metabolism of PHA-568487, a selective alpha 7 nicotinic acetylcholine receptor agonist. Drug Metab Lett 4:162-172.

Taniguchi-Takizawa T, Shimizu M, Kume T, and Yamazaki H (2015) Benzydamine $\mathrm{N}$-oxygenation as an index for flavin-containing monooxygenase activity and benzydamine
N-demethylation by cytochrome P450 enzymes in liver microsomes from rats, dogs, monkeys, and humans. Drug Metab Pharmacokinet 30:64-69.

Williams JA, Hyland R, Jones BC, Smith DA, Hurst S, Goosen TC, Peterkin V, Koup JR, and Ball SE (2004) Drug-drug interactions for UDP-glucuronosyltransferase substrates: a pharmacokinetic explanation for typically observed low exposure (AUCi/AUC) ratios. Drug Metab Dispos 32:1201-1208.

Yeung CK, Lang DH, Thummel KE, and Rettie AE (2000) Immunoquantitation of FMO1 in human liver, kidney, and intestine. Drug Metab Dispos 28:1107-1111.

Zhang J and Cashman JR (2006) Quantitative analysis of FMO gene mRNA levels in human tissues. Drug Metab Dispos 34:19-26.

Zhou D, Guo J, Linnenbach AJ, Booth-Genthe CL, and Grimm SW (2010) Role of human UGT2B10 in N-glucuronidation of tricyclic antidepressants, amitriptyline, imipramine, clomipramine, and trimipramine. Drug Metab Dispos 38:863-870.

Address correspondence to: Dr. Hong Liu, Novartis Institutes for BioMedical Research, 250 Massachusetts Avenue, Cabridage, MA 02139. E-mail: liuhx4@ yahoo.com 